\title{
A weather generator based on the European 'Grosswetterlagen'
}

\author{
Sascha Schubert \\ Meteorological Institute, Humboldt University of Berlin, Invalidenstr. 110, D-10115 Berlin, Germany
}

\begin{abstract}
The investigation of impacts of a changed climate on social and natural systems usually requires daily meteorological data on a spatial scale of about 1 to $100 \mathrm{~km}^{2}$. Even the strongest tools for the estimation of the changes in future climate, the Global Climate Models (GCMs), are not yet able to provide regional scenarios of climate change at this resolution. Presently, GCMs operate at spatial resolutions of several hundred kilometers - far too coarse for most regional analyses. Therefore, 'downscaling' approaches are needed in order to transform GCM climate change scenarios to appropriate scales for climate impact investigations. A statistical approach is developed based on the relationships between variations in regional climate and changes in large-scale circulation over the North Atlantic Ocean and Europe. Using the well-known classification scheme of circulation types, the European 'Grosswetterlagen', a conditional climatology for different large-scale air flow patterns was calculated using long daily meteorological data sets at 3 weather stations in Germany. The coupling of flow direction and climate at a site of interest varies with season and with circulation pattern. Even a single weather type produces relationships that are highly variable. A possible explanation could be the interaction of changes in mean duration time, preceding patterns or characteristic weather conditions caused by the weather type. To account for this natural variability an approach has been developed of stochastically modelling the linkage between daily weather type and regional daily weather Using long observed time series of daily surface air temperatures and precipitation, the model was calibrated and validated. Comparison of observed and simulated data demonstrated the ability of the model to adequately explain the statistical structure of the daily time series at 3 German sites. Possible applications of this model include sensitivity studies, downscaling of GCM output and investigation of the frequency and duration of extreme events.
\end{abstract}

KEY WORDS: Weather generator Stochastic simulation - Synoptic climatology ' Grosswetterlagen' Regional climate change

\section{INTRODUCTION}

In recent years, public concern about possible human-induced climate changes has increased, emphasizing the social and economic consequences of changed climatic conditions. Some efforts have been made recently to estimate the economic costs of climate change by using computer models of different natural and social systems (Mintzer 1992). Most of the systems being investigated are modelled at spatial resolutions of about 1 to $100 \mathrm{~km}^{2}$. Investigation of possible impacts of future climate change requires regional climate change scenarios at appropriate spatial scales

The strongest tools for estimating future climate, 3 dimensional coupled Global Climate Models (GCMs), are presently able to calculate atmospheric processes at a spatial resolution of several hundred kilometers, much too coarse to be used as input data in climate impact models. Moreover, the response of regional climate to global climate change is very likely to be highly inhomogeneous and cannot be assessed directly using GCMs. The estimation of regional climate changes using large-scale climate change data has been approached using downscaling techniques. Several methodologies have been developed recently, distinguishable as empirical, semi-empirical and dynamic approaches (Wigley et al. 1990, Giorgi \& Mearns 1991). While dynamic approaches are followed by embedding high-resolution models for a limited area of interest into a GCM (Giorgi et al. 1990), the semi-empirical approaches generally use statistical techniques to 
relate observed large-scale and regional climate (Karl et al. 1990, Storch et al. 1991).

Compared with observed climate, GCMs are able to more reliably simulate large-scale features of circulation in the upper atmosphere than those of surface variables such as temperature or precipitation (Houghton 1991). It is well known that in middle latitudes, regional climate is linked to the mean conditions of large-scale general circulation. Hence, changes in the frequency and the sequences of weather types and the climatic character of advected air masses will affect regional climate (Mika 1993).

In order to construct consistent scenarios of climate change at the required spatial resolution, large-scale circulation changes are linked to regional climate changes using statistical models. Following this general concept, several authors have developed methods to couple large-scale circulation indicated by different circulation parameters and regional climate in different regions of the world (Hay et al. 1992, Bogardi et al. 1993, Brinkmann 1993). Statistical approaches also include stochastic modelling to simulate local climate variability (Bardossy \& Plathe 1991, Woo 1992).

There are also problems associated with inappropriate temporal scales between GCM results and the data requirements of the climate impact models. The GCMs, created to investigate large-scale global variations in climate, often provide climate change scenarios at coarse time intervals, such as monthly or seasonally. However, investigations of climate impact require scenarios of changed 'weather', i.e. scenarios based on daily data. In some circumstances stochastic models can be used to simulate daily meteorological data for a region of interest by disaggregating monthly data (Woo 1992) and also to provide probabilities of different extreme events under changed climate conditions. This is especially important in regard to the socio-economic impacts of climate change because it has been suggested that variations in the probability and the duration of extreme events are more important than changing mean conditions (Waggoner 1989, Katz \& Brown 1992).

The coupling of several stochastic models to generate synthetic but consistent time series of several weather variables with certain statistical properties is called a weather generator (BAHC 1993). A main point of criticism of this technique is that the relationships on which the statistical model is based might change as climate changes. This may occur as the characteristic meteorological conditions of the air masses related to certain weather types are modified

This paper introduces an approach of generating daily meteorological data at a point using statistical relationships between large-scale circulation parameters and climate variables at a given site. The statistical relationships between circulation over Europe, indi- cated by the 'Grosswetterlagen' (GWL) over Europe (Hess \& Brezowsky 1976), and the climate at the investigated points are generally significant. This is true even though the changing frequency distribution of the GWL observed during the last $100 \mathrm{yr}$ is not suitable to satisfactorily explain the climate changes examined in the past. This is partly due to the high day-to-day variability of the weather related to similar large-scale air flow directions. In addition to the meteorological characteristics of air masses associated with certain weather types, the interaction of several additional components may affect daily weather. For instance, surface air temperature is correlated with the duration of the weather type, especially if the circulation pattern is linked with clear sky conditions. Moreover, temperature on the current day depends on the conditions of the previous day, and hence on the sequence of weather types. Finally, long-term variations in the characteristic meteorological features associated with a single weather type were investigated.

The method of stochastic modelling was selected to simulate sequences of daily meteorological variables at a given site conditioned on the sequence of weather types. After introducing the methodology of classifying weather types and the stochastic model, a synoptic climatology conditioned on weather type is developed. Using daily time series of 3 German weather stations, this synoptic climatology is employed to calibrate the model. Finally, some results of model validation are shown, followed by some conclusions concerning possible causes of the high natural variability of the discovered relationships.

\section{CLASSIFICATION OF WEATHER TYPES}

In the last few years investigation of changes in atmospheric circulation conditions using classified parameters of the general circulation has found growing application in climate research, especially in relation to the downscaling problem (Hay et al. 1992, Bogardi et al. 1993, Brinkmann 1993). The procedure of classifying the GWL over Europe is based on the location of steering pressure centers, the path of the frontal zone, and the type of rotation, cyclonic or anticyclonic. Generally based on surface pressure maps in the first half of the century, the development of aerology in the 1940 s forced a modification of the classification method to a stronger emphasis on flow direction at the height of $500 \mathrm{hPa}$. The last edition of the GWL catalogue (Gerstengarbe \& Werner 1993) distinguished atmospheric circulation into 29 different pressure patterns and 1 undetermined type (Table 1), resulting in a time series of daily classified GWL from 1 January 1881. to 31 December 1992. 
Table 1 Classification of the 'Grosswetterlagen' over Europe after Hess \& Brezowsky (1976)

\begin{tabular}{|c|c|c|c|}
\hline Major type & Abbr & Subtype & Abbr. \\
\hline $\begin{array}{l}\text { Zonal group } \\
\text { West }\end{array}$ & W & $\begin{array}{l}\text { 1. West, anticyclonic } \\
\text { 2. West, cyclonic } \\
\text { 3. Southern West } \\
\text { 4. Angleformed West }\end{array}$ & $\begin{array}{l}\text { Wa } \\
W z \\
W S \\
W W\end{array}$ \\
\hline $\begin{array}{l}\text { Mixed group } \\
\text { Southwest }\end{array}$ & SW & $\begin{array}{l}\text { 5. Southwest, anticyclonic } \\
\text { 6. Southwest, cyclonic }\end{array}$ & $\begin{array}{l}\text { SWa } \\
\text { SWz }\end{array}$ \\
\hline Northwest & NW & $\begin{array}{l}\text { 7. Northwest, anticyclonic } \\
\text { 8. Northwest, cyclonic }\end{array}$ & $\begin{array}{l}\text { NWa } \\
\text { NWz }\end{array}$ \\
\hline $\begin{array}{l}\text { Central European } \\
\text { high }\end{array}$ & HM & $\begin{array}{l}\text { 9. Central European high } \\
\text { 10. Central European ridge }\end{array}$ & $\begin{array}{l}\mathrm{HM} \\
\mathrm{BM}\end{array}$ \\
\hline $\begin{array}{l}\text { Central European } \\
\text { low }\end{array}$ & TM & 11. Central European low & TM \\
\hline $\begin{array}{l}\text { Meridional group } \\
\text { North }\end{array}$ & $\mathrm{N}$ & $\begin{array}{l}\text { 12. North, anticyclonic } \\
\text { 13. North, cyclonic } \\
\text { 14. North, Iceland high, anticyclonic } \\
\text { 15. North, Iceland high, cyclonic } \\
\text { 16. British Islands high } \\
\text { 17. Central European trough }\end{array}$ & $\begin{array}{l}\mathrm{Na} \\
\mathrm{Nz} \\
\mathrm{HNa} \\
\mathrm{HNz} \\
\mathrm{HB} \\
\mathrm{TrM}\end{array}$ \\
\hline Northeast & NE & $\begin{array}{l}\text { 18. Northeast, anticyclonic } \\
\text { 19. Northeast, cyclonic }\end{array}$ & $\begin{array}{l}\text { NEa } \\
\text { NE: }\end{array}$ \\
\hline East & E & $\begin{array}{l}\text { 20. Fennoscandian high, anticyclonic } \\
\text { 21. Fennoscandian high, cyclonic } \\
\text { 22. Norwegian Sea-Fennoscandian } \\
\text { high, anticyclonic } \\
\text { 23. Norwegian Sea-Fennoscandian } \\
\text { high, cyclonic }\end{array}$ & $\begin{array}{l}\text { HFa } \\
\text { HFz } \\
\text { HNFa } \\
\text { HNFz }\end{array}$ \\
\hline Southeast & $\mathrm{SE}$ & $\begin{array}{l}\text { 24. Southeast, anticyclonic } \\
25 . \text { Southeast, cyclonic }\end{array}$ & $\begin{array}{l}\mathrm{SEa} \\
\mathrm{SEz}\end{array}$ \\
\hline South & S & $\begin{array}{l}\text { 26. South, anticyclonic } \\
\text { 27. South, cyclonic } \\
\text { 28. British Islands low } \\
\text { 29. Western Europe trough }\end{array}$ & $\begin{array}{l}\text { Sa } \\
\text { Sz } \\
\text { TB } \\
\text { TrW }\end{array}$ \\
\hline
\end{tabular}

\section{THE WEATHER GENERATOR MODEL}

A statistical model was developed with the capability to simulate daily values of the forementioned meteorological variables conditioned by the occurring weather type. The model accounts for the interrelation between the variables persistence and correlation - and the seasonal variations of each of the simulated variables. The general concept divides the model in 2 parts - precipitation and temperature - which are linked by the weather type on each day. This is necessary because, in contrast to daily temperature, daily rainfall cannot be fitted by a normal distribution.

\section{Simulation of daily precipitation}

A vast number of approaches to simulating the precipitation process have been documented in the literature. An excellent review has been given by Waymire \& Gupta (1981). Most models distinguish between the occurrence and the amount of rainfall on days with precipitation, which are simulated separately. This concept is also used in the model in this paper. In recent literature some more complex models can be found simulating precipitation as a single process using power transformation techniques (Bardossy \& Plathe 1991).

To find a good compromise between simplicity in estimating model parameters and adequacy of the model, a first-order Markov chain was chosen to simulate the occurrence of rainfall. An in-

Despite the long record, the frequency of some GWL is too low for statistical investigation. Therefore, subtypes were clustered into weather types by ignoring the classification of cyclonic and anticyclonic types, following the suggestion of Gerstengarbe \& Werner (1993) (Table 1). This leads to the distinction of 10 major types (weather types), mainly distinguished by the direction of air flow and the position of the steering pressure centers. During the long history of classifying circulation into GWL, there have been several modifications to the definitions of the classes and also of the person responsible for the classification. Despite the disadvantages of this subjective classification method, the time series can be seen as homogeneous in the statistical sense (Bardossy \& Caspary 1990). dicator series of a discrete random variable $Y(t)$ is created by classifying the days into dry and wet days. If the daily rainfall amount $h$ exceeds a certain threshold (in this case $0.2 \mathrm{~mm}$ ) the day is wet; otherwise it is dry.

$$
\text { Indicator series } Y(t)=\left\{\begin{array}{cc}
0 & h \leq 0.2 \mathrm{~mm} \\
1 & h>0.2 \mathrm{~mm}
\end{array}\right.
$$

The random variable $Y(t)$ is assumed to possess the properties of a Markov-1 chain. That is, the probability of rain on day $t$ is dependent only on the state of the previous day $t-1$. The Markov-1 process is fully described by 4 transition probabilities $p^{l}{ }_{k, j}$, which are calculated conditioned by the weather type $A(t)=\alpha^{\prime}$.

$$
\begin{gathered}
P^{\prime}{ }_{k, 1}=P\left[Y(t)=1 \mid Y(t-1)=k, A(t-1)=A(t)=\alpha^{\prime}\right](2) \\
k=1,0 ; i=1, \ldots, 10
\end{gathered}
$$


Then the transition matrix can be calculated for each weather type $\alpha$

$$
p_{1,1}^{i}+p_{1,0}^{i}=1 \quad p_{0,1}^{i}+p_{0,0}^{\prime}=1
$$

To match seasonal variations, the conditioned probabilities of rain are separately calculated for each month. Compared with a uniformly distributed random number $\omega(0<\omega<1)$ the day is classified as either wet or dry following Eq. (4a) or (4b) respectively. In the case of changing weather types, no persistence is applied and the unconditioned probability of rain regarding the weather type $\alpha^{1}$ is used (Eq. $4 a$ ), while the occurrence of precipitation is assumed to depend on the previous day if the weather type remains the same (Eq. 4b)

$$
\begin{aligned}
& \text { if } A(t-1) \neq A(t)=\alpha^{1} \\
& Y(t)=1 \quad \text { if } \omega \leq \mathrm{p}_{1}^{1}
\end{aligned}
$$

and

$$
\begin{aligned}
& \text { if } Y(t-1)=1 \text { and } A(t-1)=A(t)=\alpha^{\prime} \\
& Y(t)=1 \quad \text { if } \omega \leq p_{1,1}^{\prime} \\
& \text { if } Y(t-1)=0 \text { and } A(t-1)=A(t)=\alpha^{i} \\
& Y(t)=1 \quad \text { if } \omega \leq p_{0,1}^{j}
\end{aligned}
$$

If a day is determined to be wet, the daily rainfall amount is fitted by a 2-parameter Gamma distribution, also conditioned by the weather type $\alpha^{\prime}$.

$$
F^{\prime}(z)=\frac{\left(\lambda^{i}\right)^{\beta^{\prime}}}{\Gamma\left(\beta^{\prime}\right)} \int_{0}^{z} z^{\beta^{\prime}-1} e^{-\lambda^{\prime} z} \mathrm{~d} z
$$

The parameters of the Gamma distribution are calculated using the momentum method

$$
\lambda^{\prime}=\frac{\bar{r}^{i}}{\left(s^{i}\right)^{2}} \quad \beta^{i}=\frac{\left(\bar{r}^{i}\right)^{2}}{\left(s^{i}\right)^{2}}
$$

where $\bar{r}^{\prime}$ describes the mean and $s^{i}$ the standard deviation of the daily rainfall amount in the case of occurrence of weather type $\alpha^{2}$.

\section{Simulation of daily temperatures}

The model of surface air temperature is mainly based on the approach of Richardson (1981), who developed a multivariate autoregressive model of first order to simulate daily time series of meteorological variables. The parameters of the model were conditioned by the precipitation state of the day (wet or dry). This concept has been modified, conditioning the parameters by the weather types instead of the precipitation.

Daily surface air temperature is considered to be a stochastic variable aggregated by the interaction of different components. The model of daily temperature
$T(t)$ is created by linearly adding the effects of the seasonal cycle $C(t)$, a temperature anomaly $D^{\prime}(t)$ and a random term $\eta^{i}(t)$, the latter 2 depending on the occurrence of the weather type $\alpha^{i}$.

$$
T(t)=C(t)+D^{i}(t)+\eta^{\prime}(t)
$$

The seasonal cycle of the temperature series $C(t)$ was expressed by calculating the daily mean for each day over the period of investigation. In a next step the seasonal cycle was removed by computing the daily departures from this long-term daily mean. The remaining time series with a mean value of zero shows a sequence of short-term cold and warm waves, which are assumed to be caused by the sequence of the weather types. These oscillations are modelled using the synoptic climatology conditioned on the weather types to be explained in the following section.

Besides the effects of the seasonal cycle and the sequences of different weather types, the persistence of surface air temperature and the correlations between the modelled values have to be taken into account in order to generate consistent time series of several daily meteorological variables. A multivariate autoregressive model of first order (Eq. 8a) was applied to model the random term $\eta^{i}(t)$ in Eq. (7).

An anomaly $\chi_{j}^{i}(t)$ of parameter $j$ at day $t$ is simulated by the linear combination of 2 parts: (1) a part caused by the influence of the anomaly of the previous day $\chi_{j}^{\prime}(t-1)$, and (2) a random part $\varepsilon_{j}(t)$, which is normally distributed with a mean of zero and a variance of unity.

The model is of first order because only the temperature anomaly of the previous day $t-1$ is taken into account.

$$
\chi_{j}^{\prime}(t)=A_{i}(t) \chi_{j}^{i}(t-1)+B_{i}(t) \varepsilon_{j}(t)
$$

The matrices $\mathbf{A}_{i}$ and $\mathbf{B}_{i}$, both varying with time $(t)$ and with the weather types (i), are calculated to conserve the serial and the cross correlation of the observed time series in the new sequences. If the weather type $\alpha^{\prime}$ remains the same on successive days the model parameters are conditioned by that pattern, otherwise, the unconditioned correlation coefficients are used to calculate the matrices $\mathbf{A}$ and $\mathbf{B}$

To preserve the variability of the process, the random term $\eta^{i}(t)$ is calculated by scaling the random anomaly $\chi_{i}^{j}(t)$ with the conditioned standard deviation $\sigma_{j}^{\prime}(t)$

$$
\eta^{i}(t)=\sigma_{j}^{i}(t) \chi_{j}^{j}(t)
$$

The use of a multivariate approach implies the assumption of normally distributed variables. Applying Eqs. (7) and (8b), a time series of the residuals $\chi_{j}^{\prime}(t)$ was created by removing both the seasonal cycle and standardising the remaining daily anomalies using the statistical parameters conditioned by the weather types $\alpha^{\prime}$. 


$$
\chi_{j}^{i}(t)=\frac{T_{j}(t)-C_{j}(t)-D_{j}^{i}(t)}{\sigma_{j}^{j}(t)}
$$

This procedure is illustrated in Fig. 1 In the upper panel the seasonal cycle of the long-term daily mean of the daily maximum temperature is shown overlying a series of actual daily values. In the middle panel the resulting time series of the daily anomalies sequences of short-term cold and warm waves is illustrated together with the mean temperature anomalies caused by the weather types according to the conditional synoptic climatology. It can be seen that only a part of the day to day variance in the time series can be explained due to sequence of different air masses associated with different weather types. In the lower panel the time
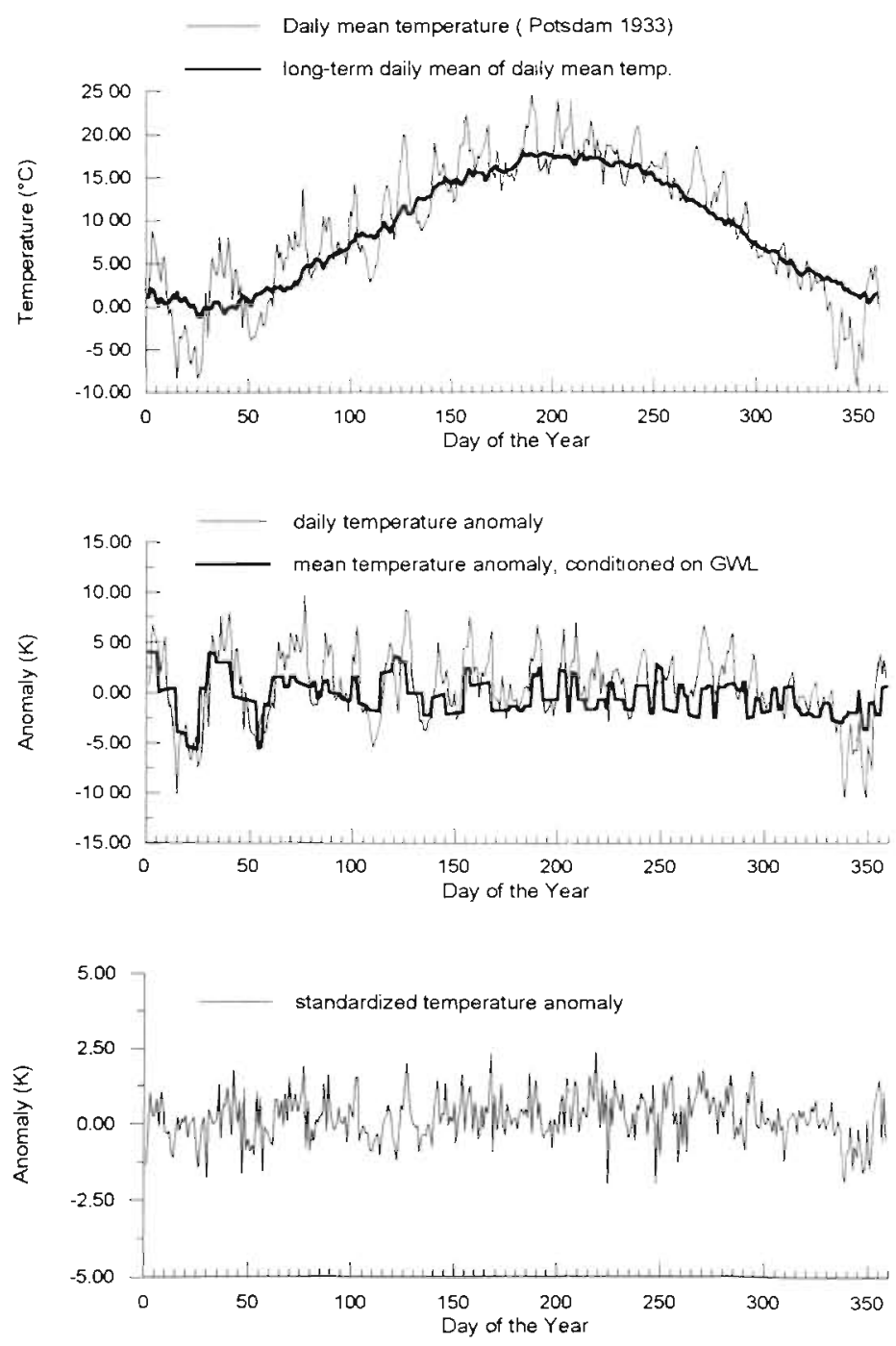

Fig. 1. Example of reducing the series of daily values to a series of normally distributed residuals conditioned by circulation patterns (see Eq. 9) series of the temperature residuals is shown, being stationary with zero mean and standard deviation of unity. To improve the fit of the seasonal cycle of the statistical parameters, the monthly means were expressed by Fourier transformation (Woolhiser \& Roldan 1986). Using the Fourier coefficients, the daily mean temperature anomaly and the daily mean standard deviation, conditioned on the weather type, have been calculated from the monthly values.

The daily meteorological values are generated as follows. Firstly, an anomaly is simulated using the autoregressive approach in Eq. (8a). To conserve the natural variability of the parameters this anomaly is scaled by the daily standard deviation depending on the current weather type. The actual daily variables are modelled by adding the conditioned daily mean value and the seasonal cycle (see Eq. 7). The seasonal variation of all the model parameters is fitted using Fourier coefficients. This multivariate autoregressive technique allows simulation of synthetic and consistent daily time series providing a rather comprehensive explanation of the statistical structure of the time series. In addition, the mean conditions, the natural variability and the distribution of the observed sequences are described. This is especially important for investigating the changes in the probability and the duration of extreme events. It was found that natural systems, e.g. agricultural crops, are much more sensitive to the passing of certain thresholds than to changes in the mean conditions (Mearns et al. 1984, Wang et al. 1992).

\section{A SYNOPTIC CLIMATOLOGY OF THE WEATHER TYPES}

To establish the model parameters by using the relationships between weather types and climate at single stations, a synoptic climatology of the weather types was calculated for each station. The meteorological data used here are daily data of surface air temperature (mean, minimum and maximum) and daily rainfall amount at 3 German weather stations representing different climate areas (Table 2). Using certain thresholds, days of events can be calculated from the temperature data, which are important for assessments of climate impact on different systems:

Hot days: $T_{\max } \geq 30^{\circ} \mathrm{C}$

Summer days: $T_{\max } \geq 25^{\circ} \mathrm{C}$

Frost days: $T_{\min }<0^{\circ} \mathrm{C}$

Ice days: $T_{\max }<0^{\circ} \mathrm{C}$ 
Table 2. Weather stations used in the investigation

\begin{tabular}{llccc|}
\hline Station & Area & Location & Altitude (m) & Period of time \\
\hline Hamburg & Coast & $53.6^{\circ} \mathrm{N}, 10.0^{\circ} \mathrm{E}$ & 16 & 1 January 1915 to 31 December 1991 \\
Potsdam & Inland & $52.2^{\circ} \mathrm{N}, 13.0^{\circ} \mathrm{E}$ & 81 & 1 January 1893 to 31 December 1989 \\
Munich & Foothills & $48.1^{\circ} \mathrm{N}, 11.6^{\circ} \mathrm{E}$ & 520 & 1 January 1879 to 31 December 1984
\end{tabular}

\section{Temperature}

The thermal character of a weather type is largely dominated by its accompanying air masses. The meteorological features of the air masses are mainly related to their source regions, although a transformation of these mean characteristics can take place on the track from the source to Central Europe. This transformation is one of the reasons for the high variability of the daily temperature values usually related to a certain weather type. The temperature anomalies $D_{j}^{i}(t)$ are calculated as follows: the seasonal cycle of the daily variables was removed by calculating the deviations from the longterm daily mean values. The remaining departures from the mean have been conditioned by the weather types $\alpha^{i}$ and averaged for every month of the year.

$$
D_{j}^{j}(t)=\frac{1}{N^{i}(t)} \sum_{k=1}^{N^{\prime}(t)}\left[T_{j, k}(t)-C_{j}(t) \mid A_{k}(t)=\alpha^{i}\right]
$$
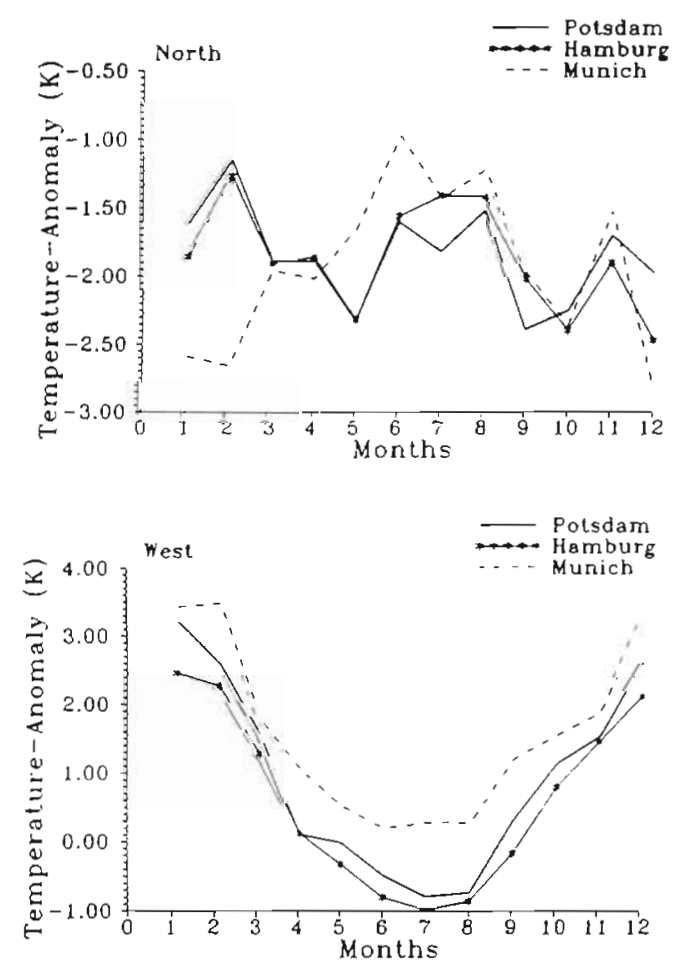

where $D_{j}^{\prime}(t)$ is the monthly averaged daily anomaly of parameter $j$ conditioned by weather type $\alpha^{i}, T_{j, k}(t)$ is the daily value of parameter $j$ on day $t_{i} C_{j}(t)$ is the long-time daily mean of parameter $j$ on day $t$, and $N^{3}(t)$ is the absolute frequency of weather type $\alpha^{i}$.

As can be seen in Fig. 2, even the monthly averaged mean temperature anomalies linked to a single weather type show a seasonal cycle caused by the seasonal variations of the thermal properties of the communicating air masses.

The mean temperature conditions, associated with westerly air flow (westerlies, see Table 1), that occurred are strongly influenced by the thermal stability of the North Atlantic Ocean. Therefore, the seasonal cycle of the temperature conditioned by the westerlies can be described as maritime with negative temperature anomalies in summer and positive ones in winter. If the air has come from an easterly direction (easterlies, see Table 1) the seasonal cycle of the monthly
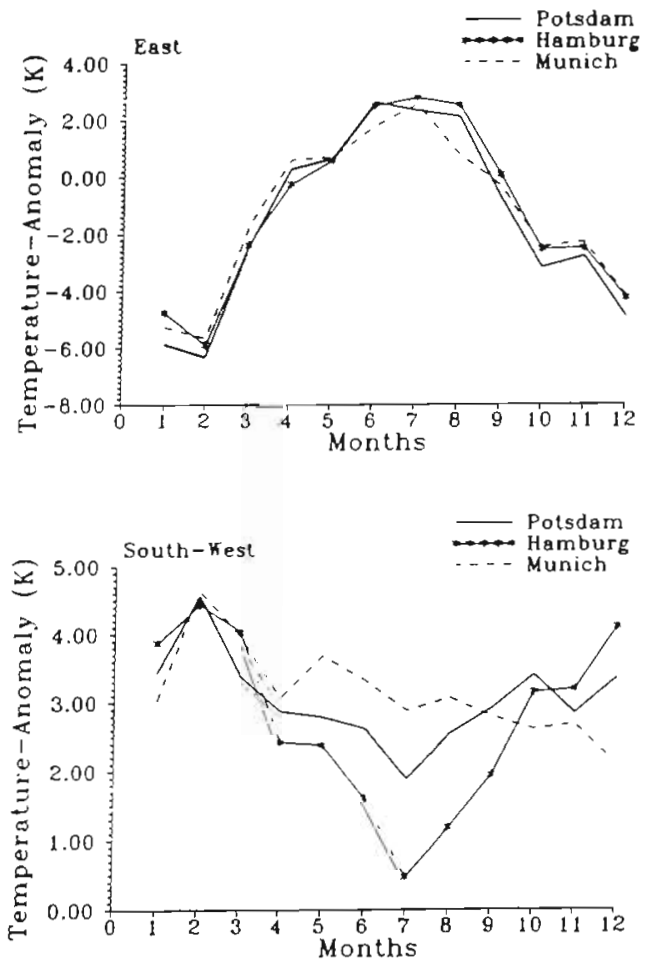

Fig. 2. Seasonal cycle of monthly averaged mean daily anomalies from daily mean temperature conditioned by several weather types at 3 German weather stations 
mean temperature anomalies is characterised by a pronounced amplitude. At all 3 stations under eastern air flow there are strong negative temperature anomalies in winter and strong positive temperature deviations in summer. In most of the cases these weather types are related to the extreme temperature events (days with the lowest minimum and highest maximum temperatures respectively) of the year.

By comparing the 3 stations, some regional peculiarities are also revealed. While larger regional temperature differences have been observed if the air has come from the southwest, the monthly means are quite uniform at all stations under easterly airflow. The influence of the ocean seems to become weaker with growing distance from the coast. Usually the summer temperatures at Munich, situated near the Alps, are higher under weather types associated with maritime air masses (W, SW, N) than at Hamburg and Potsdam which are closer to the coast. As is seen in Table 3, the daily temperature residuals remaining after standardising the series according to Eq. (10) are normally distributed with zero mean and standard deviation of unity and hence no longer dependent either on time or on the weather type. Thus, they can be expressed by a standard Gaussian distribution, which is also indicated by the high significance levels of the KolmogorovSmirnov test. The high values of serial correlation in the remaining time series suggest that the procedure of standardizing is not suitable to account for the persistence of the temperature, which therefore has to be included in the model.

\section{Precipitation}

The mean precipitation process is described by the rainfall occurrence process and the distribution of daily rainfall amounts on a wet day. The rainfall occurrence is simulated using a first-order Markov chain with 4 transition probabilities fully describing the model (see Eq. 2). These probabilities $p_{j, k}^{i}(t)$ can quite easily be estimated by the frequencies of the days according to the character of the transition and conditioned by the weather type and the month of the year.

$$
p_{j, k}^{i}(t)=\frac{N_{j, k}^{i}(t)}{N_{k}^{i}(t)} \quad j, k=0,1
$$

The mean rainfall amount on a wet day is estimated by the momentum method (Eq. 12) using the absolute monthly rainfall amount $R^{\prime}(t)$ and the total number of wet days $N_{1}^{\prime}(t)$ conditioned by the weather types.

$$
\bar{r}^{t}(t)=\frac{R^{\prime}(t)}{N_{1}^{i}(t)}
$$

Table 3. Statistical parameters of the residuals series of mean, minimum and maximum temperature $(T)$ at the weather stations Potsdam, Hamburg and Munich. Skew.: skewness; Cur: curtosis; Corr: serial correlation (lag 1); Sig.: Kolmo-

\begin{tabular}{|c|c|c|c|c|c|c|}
\hline & Mean & $S D$ & Skew. & Cur. & Corr & Sig. \\
\hline \multicolumn{7}{|c|}{ Potsdam } \\
\hline$T_{\text {mean }}$ & 0.01 & 1.04 & -0.01 & 3.47 & 0.66 & 0.66 \\
\hline$T_{\min }$ & 0.01 & 1.04 & -0.26 & 3.41 & 0.60 & 0.60 \\
\hline$T_{\max }$ & 0.02 & 1.04 & 0.09 & 3.39 & 0.61 & 0.64 \\
\hline \multicolumn{7}{|c|}{ Hamburg } \\
\hline$T_{\text {mean }}$ & 0.02 & 0.99 & -0.02 & 3.28 & 0.67 & 0.21 \\
\hline$T_{\min }$ & 0.01 & 0.99 & 0.10 & 3.17 & 0.63 & 0.18 \\
\hline$T_{\max }$ & 0.02 & 0.99 & -0.34 & 3.40 & 0.58 & 0.14 \\
\hline \multicolumn{7}{|l|}{ Munich } \\
\hline$T_{\text {miean }}$ & 0.01 & 1.09 & -0.10 & 3.63 & 0.70 & 0.33 \\
\hline$T_{\min }$ & 0.01 & 1.10 & -0.31 & 3.77 & 0.67 & 0.31 \\
\hline$T_{\max }$ & 0.01 & 1.09 & 0.02 & 3.45 & 0.63 & 0.26 \\
\hline
\end{tabular}
gorov-Smirnov test of significance

The distribution of the daily rainfall amount is strongly skewed, rejecting the assumption of a Gaussian model. Using the nonparametric KolmogorovSmirnov test all samples of rainfall amounts conditioned on the weather type have been checked against the hypothesis of following a 2-parameter Gamma distribution. In $90 \%$ of all cases this assumption cannot be rejected at a significance level of $\mathrm{p}<$ 0.10 (Table 4). Samples with a number of cases lower than 20 were not included in the test. All distributions significantly deviating from the assumption of following a Gamma distribution are indicated (bold: $\mathrm{p} \leq$ 0.05 ; italic: $p \leq 0.10$ j As illustrated in Fig. 3, the parameters of the precipitation process possess a seasonal cycle which also varies with the weather types. In general, the highest mean daily rainfall amounts on a wet day can be observed in summer for all weather

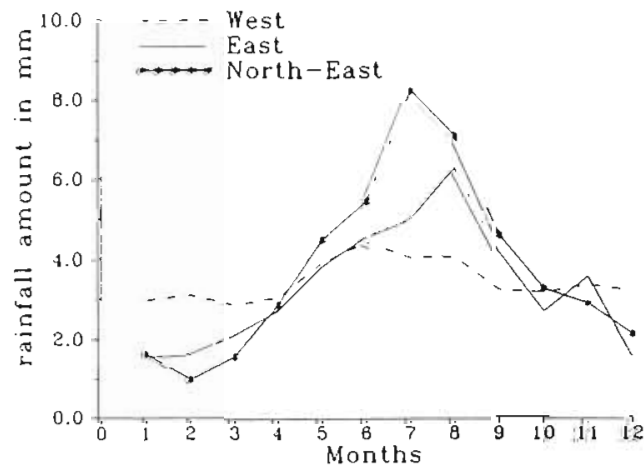

Fig. 3. Seasonal cycle of monthly averaged mean daily rainfall amount on wet days conditioned by the circulation patterns West, East and Northeast at Potsdam 
Table 4. Significance level of the Kolmogorov-Smirnov test for daily rainfall data fitted by a 2-parameter Gamma distribution. GWL: 'Großwetterlagen' (see Table 1). Italic type indicates $0.05<\mathrm{p} \leq 0.10$; bold type indicates $\mathrm{p}<0.05$ (i.e. the hypothesis of equal distributions can be rejected with a probability of $>95 \%$ )

\begin{tabular}{|lcccccccccccc} 
GWL & Jan & Feb & Mar & Apr & May & Jun & Jul & Aug & Sep & Oct & Nov & Dec \\
\hline W & $\mathbf{0 . 0 2}$ & 0.25 & 0.12 & 0.21 & $\mathbf{0 . 0 3}$ & 0.44 & 0.26 & 0.09 & 0.13 & 0.08 & 0.14 & 0.10 \\
SW & 0.87 & 0.44 & 0.83 & 0.94 & 0.85 & 0.34 & 0.90 & 0.92 & 0.24 & 0.74 & 0.19 & 0.67 \\
NW & 0.53 & 0.24 & 0.95 & 0.29 & 0.40 & 0.82 & 0.47 & 0.55 & 0.83 & 0.80 & 0.48 & 0.64 \\
HM & 0.12 & 0.33 & 0.38 & 0.60 & 0.51 & 0.09 & 0.65 & 0.36 & 0.25 & 0.96 & 0.07 & 0.23 \\
TM & 0.99 & 0.82 & 0.44 & 0.62 & 0.68 & 0.84 & 0.66 & 0.10 & 0.86 & 0.72 & 0.47 & - \\
N & 0.82 & 0.10 & 0.03 & 0.19 & 0.14 & 0.18 & 0.62 & 0.12 & 0.66 & $\mathbf{0 . 0 5}$ & 0.44 & 0.35 \\
NE & 0.77 & 0.64 & 0.66 & 0.31 & 0.37 & 0.69 & 0.46 & 0.95 & 0.92 & 0.99 & - & 0.86 \\
E & 0.46 & 0.33 & 0.96 & 0.86 & 0.61 & 0.85 & 0.87 & 0.73 & 0.17 & 0.65 & 0.69 & 0.91 \\
SE & 0.87 & 0.70 & 0.91 & 0.59 & - & - & - & - & - & 0.84 & 0.98 & 0.83 \\
S & 0.27 & 0.74 & 0.40 & 0.44 & 0.98 & 0.45 & 1.00 & 0.32 & 0.44 & $\mathbf{0 . 0 5}$ & 0.12 & 0.60 \\
\hline
\end{tabular}

types. That is obviously caused by the relationship between the maximum pressure of water vapor and air temperature. The daily rainfall amounts occurring under westerlies, which are mainly related to frontal precipitation, are much smaller in summer than those of the weather type Northeast, mainly caused by convective precipitation.

a

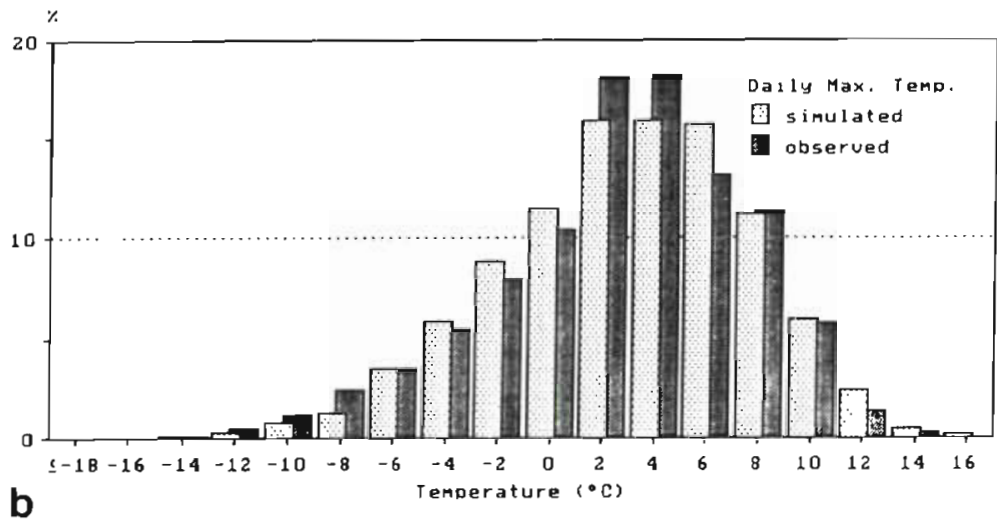$$
\text { b }
$$

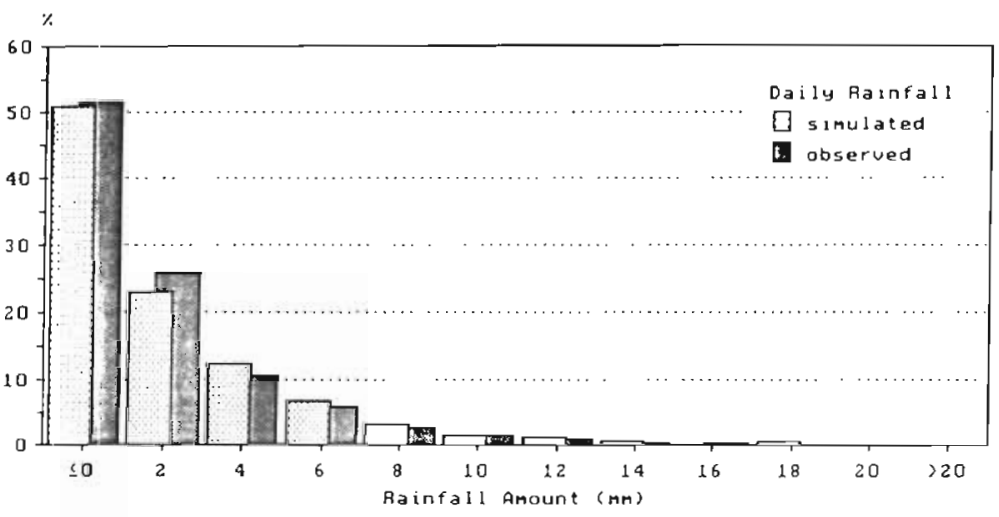

Fig. 4. Comparison of the distribution of anomalies from the long-term daily mean of (a) dally maximum temperature and (b) daily rainfall amounts in January, simulated with the stochastic model and observed at Hamburg, 1954 to 1991

\section{VERIFICATION OF THE MODEL}

Using the observed data sets of the 3 German weather stations (see Table 2), the model was applied to the record of the GWL over Europe. To ensure independence in evaluating the model, the data records were divided into 2 parts. The first part of the meteorological time series was used to calibrate the model parameters and the second part was used to prove the ability of the model to simulate the observed climate. Fig. 4a shows the frequency distributions of the observed and the simulated daily maximum temperature in Hamburg in January during the period 1954 to 1991. Despite the differences in some of the classes, a good agreement can be seen even at the tails of the distribution. It should be noticed that the model is able to reproduce the slight skewness of the temperature distribution in January, usually causing stronger negative than positive extremes as an effect of temperature persistence.

Fig. 4b illustrates the comparison of modelled and observed daily rainfall in January for Hamburg for the same period. The simulated series reproduces the behaviour of the observed sample, as well for the numbers of dry ( $h \leq 0.2 \mathrm{~mm}$ ) and wet days. Looking at Fig. 5 it becomes obvious that the statistics of the extremes are also well described by the model. During each year of simulation the highest daily value of the modelled and the observed values was stored for every parameter simulated. To compare the resulting time series both have been ordered in ascending order. In Fig. 5a the annual maximum of the daily maximum 
temperature is compared for the simulated and the observed values corresponding to the period 1954 to 1991 in Hamburg. Although there are some deviations in the lower part of the sample, the annual maxima show a good agreement. Looking at the annual maxima of the daily rainfall amount (Fig. 5b), the disagreements seem to occur more in the upper tail of the distribution. Nevertheless, the comparison delivers satisfying results, keeping in mind the simplicity of the model.

An important question is whether the model is able to simulate the serial correlation observed in the instrumental records, since particularly long periods of dry or wet days, causing droughts or floods, can strongly affect natural systems. In Fig. 6 the relative frequencies of the duration of periods with wet and dry days are compared for the observed and simulated series in January in Hamburg. The model slightly overestimates the very short durations of $1 \mathrm{~d}$ and is not able to simulate the very extreme durations. Generally the model is better at simulating wet periods than long dry periods.
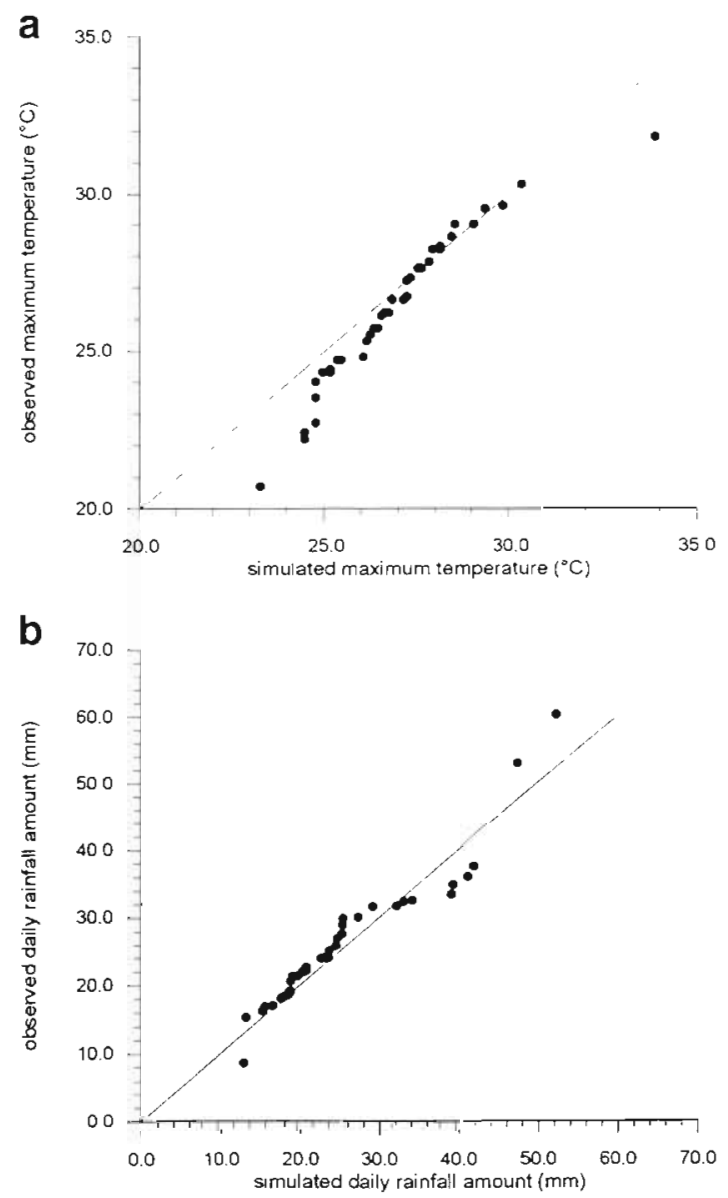

Fig. 5. Comparison of observed and simulated annual maxima of (a) daily maximum temperature and (b) daily rainfall, Hamburg, 1954 to 1991
Fig. 7 illustrates the comparison of simulated and observed distributions of the duration of spells with ice days and hot days in Hamburg during 1954 to 1991. While the relative frequency of the duration of hot days is reproduced quite well, the model does not perform as well in simulating the distribution of the duration of ice periods. The relative frequency of periods with only 1 ice day is largely overestimated by the model, while periods with extreme durations of $20 \mathrm{~d}$ cannot be simulated with this approach. This is an indication that modelling the 'memory' of the atmosphere by a firstorder Markov chain might be not adequate to simulate the real process of temperature persistence, especially in winter. Unfortunately the samples conditioned on the weather types are in generally too small to apply models of higher order.

One advantage of the simulation approach is the possibility of easily checking the sensitivity of the simulated daily meteorological variables against changes in different input parameters. The parameters to be modified, such as the frequency distribution of the
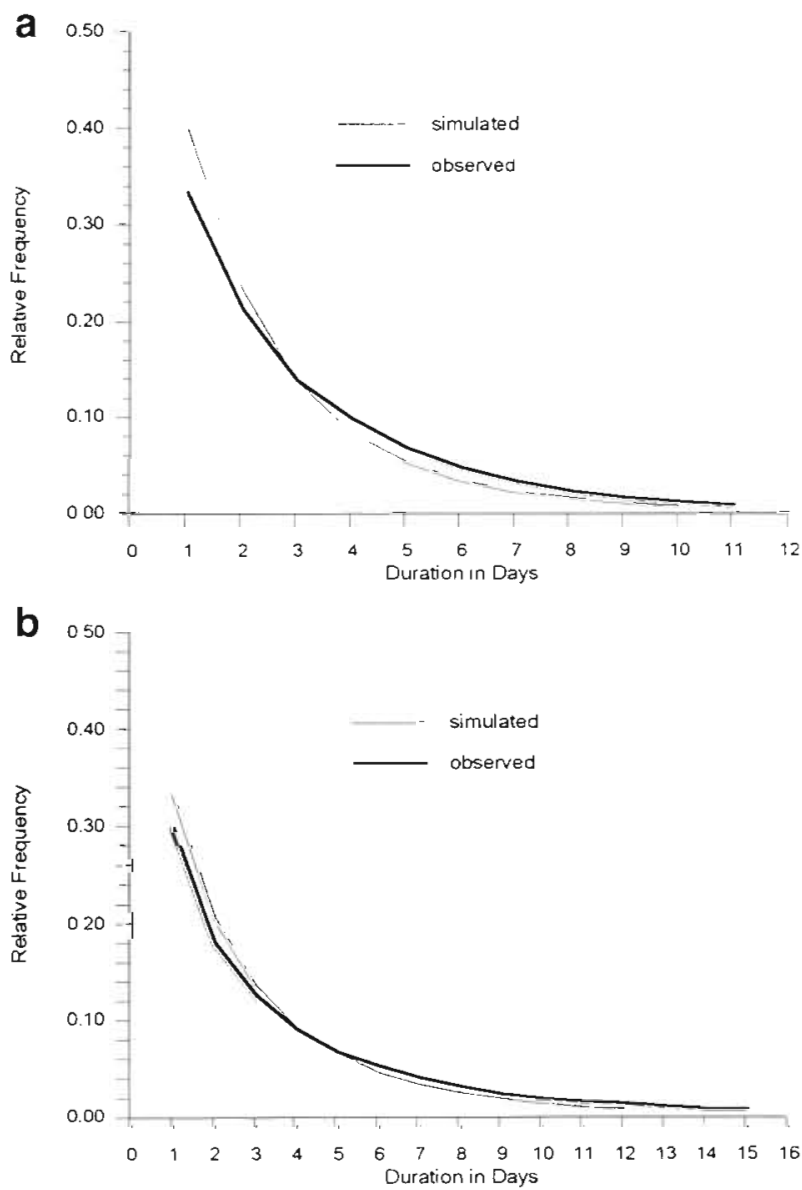

Fig. 6. Observed and simulated relative frequency of the duration of (a) wet and (b) dry periods, Hamburg, 1954 to 1991 
weather types, will be changed in an arbitrary but reasonable way to investigate several circulation states. This could constitute a first step towards producing scenarios of regional climate change on the basis of daily values. Other parameters of general circulation might be the subject of changes in the future, because historical variations have already been observed. For instance, the linkage between circulation and climate at a point of interest does not necessarily have to be stationary. On the contrary, even the mean meteorological conditions caused by a single weather type at a location can change, as illustrated in Fig. 8 for the 3 German stations. There is evidence that the air masses accompanying the easterlies (Table 1) have become warmer in summer (upper panel, Fig. 8) during the most recent decades. Starting with the beginning of the 1960 s the observed averaged daily mean temperature anomaly under the weather type East has increased by almost $3 \mathrm{~K}$. However, the westerlies tend to be associated with cooler air masses at all 3 sites
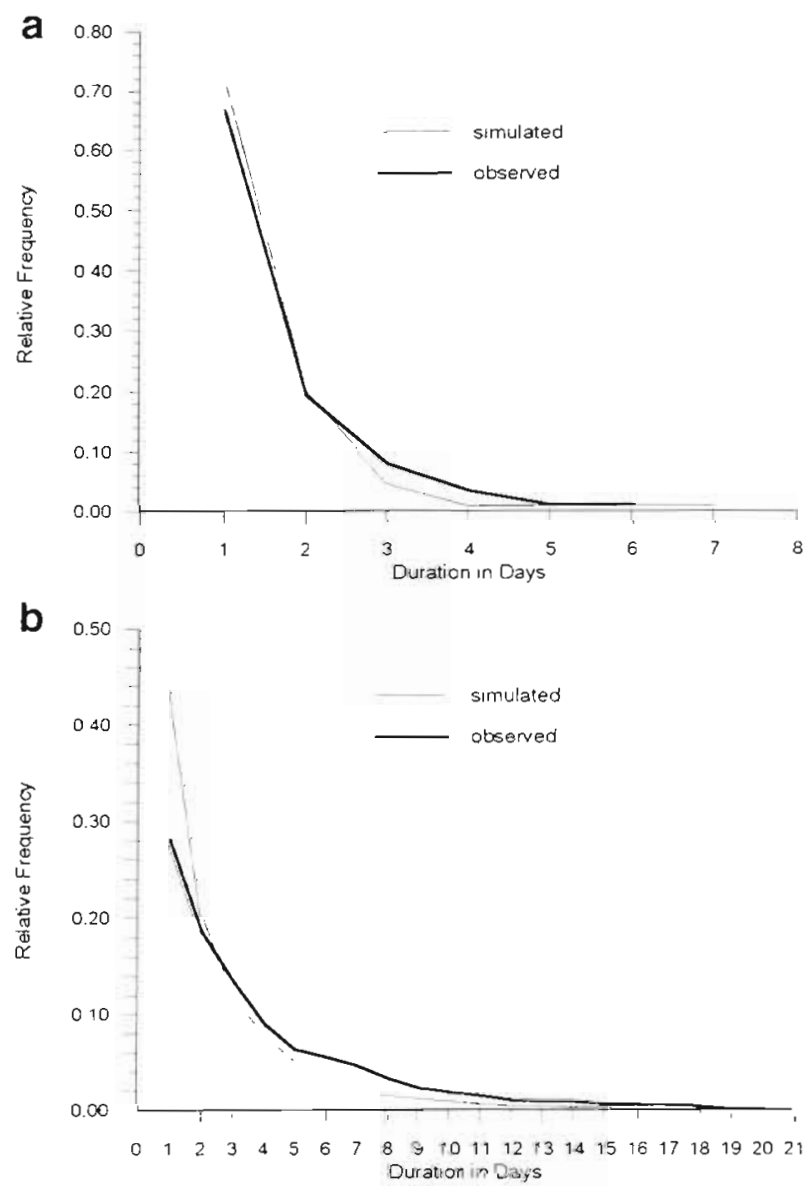

Fig. 7. Observed and simulated relative frequency of the duration of periods with (a) hot days (dally maximum temperature $\geq 30.0^{\circ} \mathrm{C}$ ) and (b) ice days (dally maximum temperature $<0^{\circ} \mathrm{C}$ ), Hamburg, 1954 to 1991
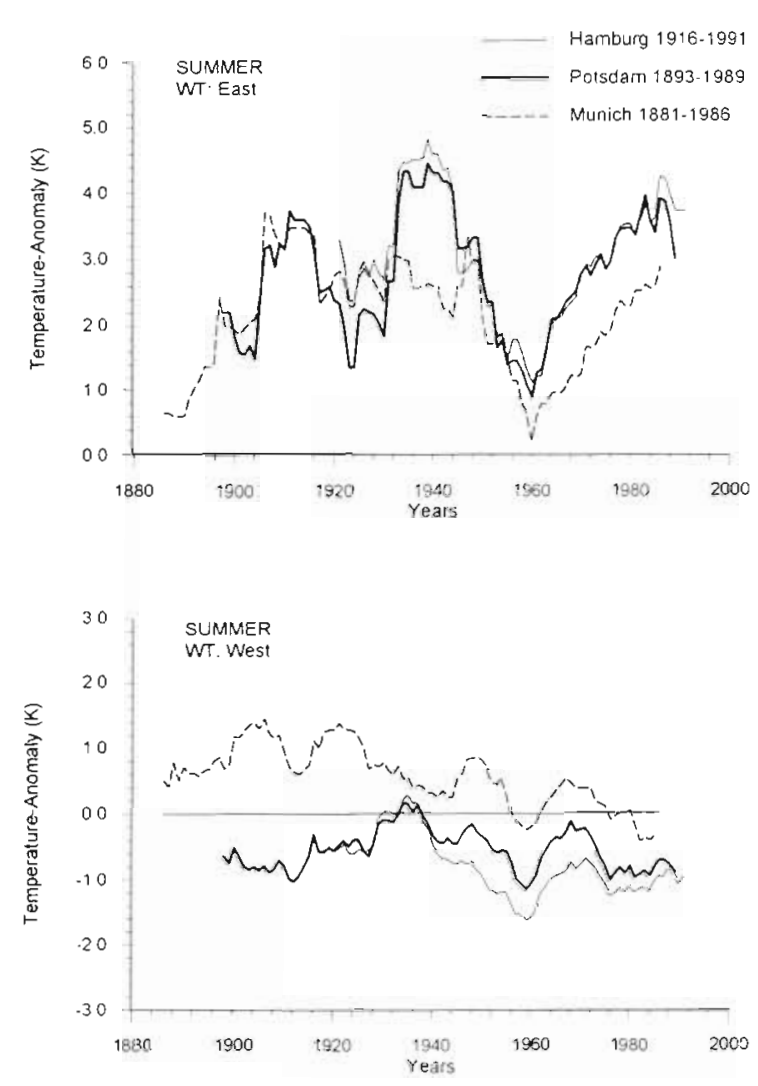

Fig. 8. Twenty year running mean variations of the seasonal mean of the anomalies from daily temperature in summer for the weather types East and West at 3 German weather stations

since the middle of the century (lower panel, Fig. 8). For instance, at Munich the daily mean temperatures coupled with zonal flow have decreased by about $1.5 \mathrm{~K}$, causing negative temperature anomalies since 1980. The mean daily precipitation on wet days has undergone long-term changes as well, although with a larger spatial variability, e.g. for easterlies and westerlies in summer (Fig 9). While the precipitation associated with easterlies has tended to become heavier at Munich during the last $50 \mathrm{yr}$, the mean daily rainfall amount under easterlies has decreased at Hamburg and no changes could be detected in Potsdam. The precipitation coupled with westerlies shows a much lower temporal variability, although a slight long-term increase of the mean daily rainfall amount on wet days is visible at Munich.

As shown in Fig. 10, the seasonal mean duration of the weather types also has changed during the period of observations, e.g. easterlies tend to last longer in summer during recent decades. The easterlies are usually associated with blocking situations over the North Atlantic, often causing clear sky conditions in Central Europe. Depending on the duration of the weather 
type, the daily meteorological variables are determined more and more by local radiation conditions than by the properties of the advected air mass. The overlapping of the long-term variations of these various parameters, such as the frequency distribution, duration time and characteristic meteorological features of the weather types, might be a reason for the high variability in the relationships between largescale circulation and local climate. For instance, the regional climatic effect of increasing frequency of easterlies in summer on the local climate can be amplified by a simultaneous increase of the duration time of this weather type and the temperature of its accompanying air masses.

In separate investigations the model might possibly quantify the influence of these different components, which in nature are in complex interaction.

\section{CONCLUSIONS}

This model applies the statistical relationships between large-scale circulation conditions and climate
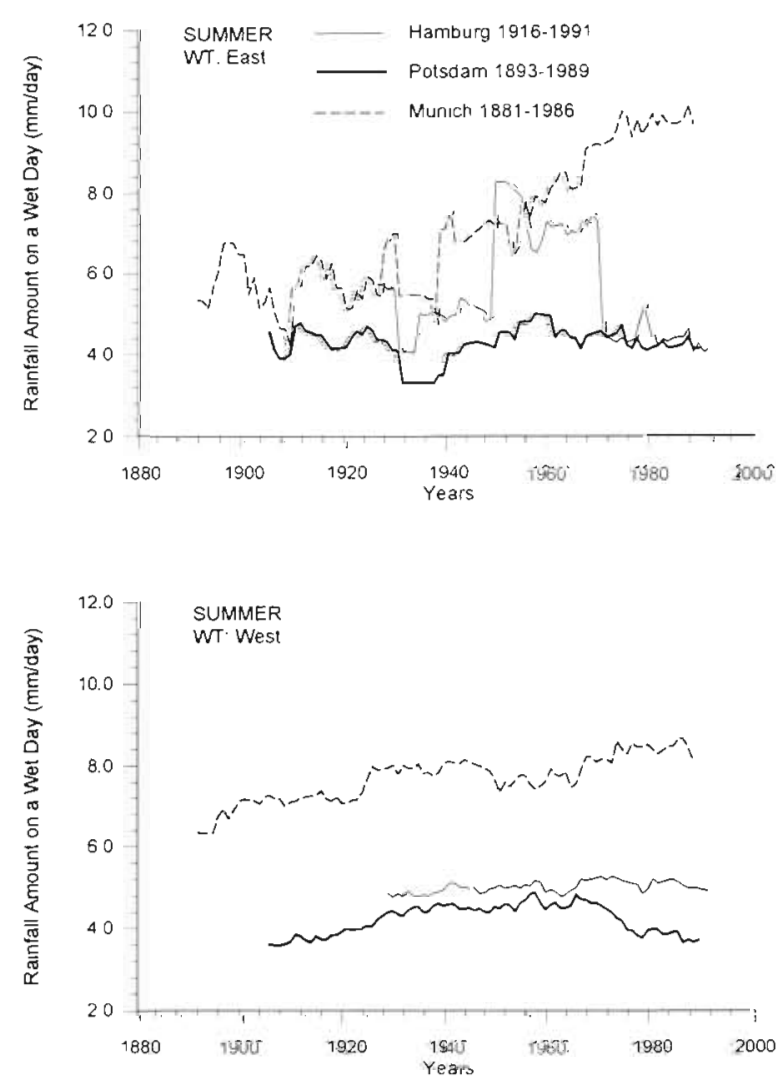

Fig. 9. Twenty year running mean variations of the seasonal mean of daily rainfall amounts on a wet day in summer for the weather types East and West at 3 German weather stations

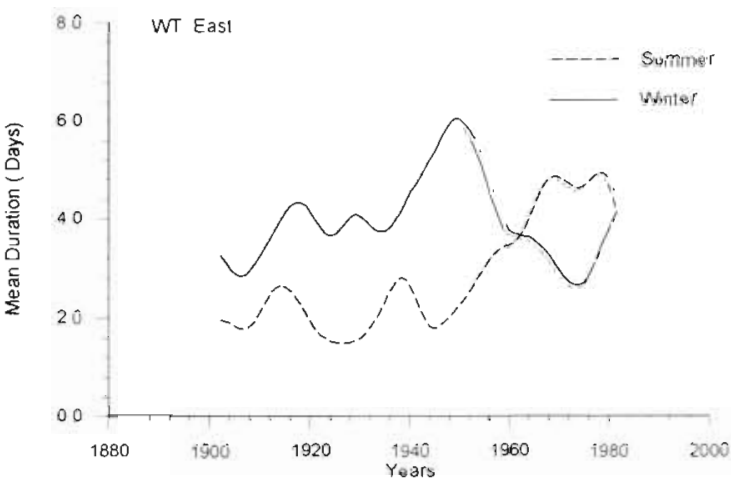

Fig. 10. Twenty year Gauss lowpass-smoothed variations of the mean duration of weather type East in summer and winter, 1881 to 1992

at single stations to stochastically generate synthetic and consistent time series of daily meteorological variables. Using this stochastic approach, future changes in the large-scale circulation, e.g. simulated by GCMs, can be interpolated for climate impact assessments of smaller scales (region, point). This seems to be important in filling the gap between the coarse resolution of the GCM scenarios and the data requirements of climate impact models. To estimate socio-economic consequences of a changing climate, not only the mean conditions but also the variations in the probability and the duration of extreme events (floods, droughts, etc.) have to be taken into account. Climate-sensitive systems such as agricultural crops react in a highly non-linear way to climate changes (Chmielewski 1992). That is, if certain thresholds are passed, certain interactions occur in order to reach a new equilibrium. The impacts of climate changes with regard to these thresholds can only be mitigated if climate scenarios are provided at an appropriate temporal scale.

Most of the natural systems modelled for climate impact assessments require climate scenarios on a daily scale that reflect the entire distribution of the meteorological input variables. Stochastic models might provide a tool to refine the monthly or seasonal temporal resolution of the GCM scenarios to shorter time scales in order to permit investigations of impacts due to changes in the probability and duration of extreme events, if the mean conditions are altered due to climate change. By arbitrarily changing the parameters of the large-scale circulation in a reasonable manner, the sensitivity of the regional climate to the variations of different components can be studied. Using the weather generator, climate impact models can be provided with regional climate change scenarios based on daily values which reflect different states of the general circulation. 
Acknowledgements. This study was supported by the Federal Ministry of Research and Technology (07KFT55A7). The paper benefited from the comments made by 2 anonymous reviewers.

\section{LITERATURE CITED}

BAHC (Biospheric Aspects of the Hydrological Cycle) (1993). Project Focus 4: the weather generator project. In: Summary report, data requirements for ecological and hydrological studies and related management purposes Workshop, Bratislava, 16-18 September 1993. The Weather Generator Project, Bratislava, Slovakia, Report no. 1

Bardossy, A., Caspary, H. J. (1990). Detection of climate change in Europe by analyzing European circulation patterns from 1881 to 1989. Theor. appl. Climatol. 42 $155-167$

Bardossy, A., Plathe, E. (1991). Modelling daily rainfall using a semi-Markov representation of circulation pattern occurrence. J. Hydrol. 122: 33-47

Bogardi, I., Matyasovszky, I., Bardossy, A., Duckstein, L. (1993). Application of a space-time stochastic model for daily precipitation using atmospheric circulation patterns J. geophys. Res. 98(D9): 16653-16667

Brinkmann, W. A. R. (1993). Development of an airmassbased regional climate change scenario. Theor appl. Climatol. 47: 129-136

Chmielewski, F.-M. (1992). Impact of climate changes on crop yields of winter rye in Halle (southeastern Germany) 1901-1980. Clim. Res. 2: 23-33

Gerstengarbe, F.-W., Werner, P. C. (1993). Katalog der Großwetterlagen nach Paul Hess und Helmut Brezowsky 1881-1992, 4. Aufl. Ber. Dt. Wetterd. 113

Giorgi, F., Marinucci, M. R., Viconti, G. (1990). Use of a limited area model nested in a general circulation model for regional climate simulation over Europe. J. geophys. Res 95: $18413-18432$

Giorgi, F., Mearns, L. O. (1991). Approaches to the simulation of regional climate change: a review. Rev. Ceophys. 29 $191-216$

Hay, L. E., McCabe, G. J., Wolock, D. M., Ayers, M. A. (1992) Use of weather types to disaggregate general circulation model predictions. J. geophys. Res. 97(D3): 2781-2790

Hess, P., Brezowsky, H. (1976). Die Großwetterlagen über Europa, 2. Aufl. Ber. Dt. Wetterd. Bd. 15, No. 113

Houghton, J. T (ed.) (1991). Scientific assessment of climatic change: summary of the IPCC working group I report. In

Editor: G. Esser, Gießen, Germany
Jäger, J., Ferguson, H. L. (eds.) Climatic change: science impacts and policy (Proceedings of the Second World Climate Conferencel. Cambridge University Press, Cambridge, p. $23-46$

Karl, T R., Wang, W. C., Schlesinger, M. E., Knight, R. W. Portman, D. (1990). A method of relating general circulation model simulated climate to the observed local climate, Part I: Seasonal statistics. J. Clim. 3: 1053-1079

Katz, R. W., Brown, B. G. (1992). Extreme events in a changing climate: variability is more important than averages. Clim. Change 21:289-302

Mearns, L. O., Katz, R. W., Schneider, S. H. (1984). Extreme high-temperature events: changes in their probabilities with changes in mean temperature. J. Clim. appl. Meteor 23: $1601-1613$

Mika, J. (1993). Effects of the large-scale circulation on local climate anomalies in relation to GCM outputs. Idoejárás $97(1): 21-34$

Mintzer, I. M. (ed.) (1992). Confronting climate change. Cambridge University Press, Cambridge

Richardson, C. W. (1981). Stochastic simulation of daily precipitation, temperature and solar radiation. Water Resour. Res. 17(1): 182-190

Storch, H. von, Zorita, E., Cubasch, U. (1991). Downscaling of global climate change estimates to regional scales: an application to Iberian rainfall in wintertime. Max-PlanckInstitut für Meteorologie Rep. No. 64, Hamburg

Waggoner, P. E. (1989). Anticipating the frequency distribution of precipitation if climate change alters its mean Agricult. For Meteor. 47:321-337

Wang, Y. P., Handoko, J., Rimmington, G. M. (1992). Sensitivity of wheat growth to increased air temperature for different scenarios of ambient $\mathrm{CO}_{2}$ concentration and rainfall in Victoria, Australia - a simulation study. Clim. Res 2: $131-149$

Waymire, E., Gupta, V. K. (1981). The mathematical structure of rainfall representations 1. A review of the stochastic rainfall models. Water Resour. Res. 17(5): 1261-1272

Wigley, T M. L., Jones, P. D., Briffa, K. R., Smith, G. (1990). Obtaining sub-grid-scale information from coarse-resolution general circulation model output. J. geophys. Res. 95: $1943-1953$

Woo, M. (1992). Application of stochastic simulation to climate-change studies. Clim. Change 20: 313-330

Woolhiser, D. A., Roldan, J. (1986). Seasonal and regional variability of parameters for stochastic daily precipitation models: South Dakota, USA. Water Resour. Res. 22: 985-978

Manuscript first received: March 2, 1994

Revised version accepted: July 18, 1994 